\begin{tabular}{|c|c|c|c|c|}
\hline & $\begin{array}{l}\text { Non-ischaemic } \\
\text { Cardiomyopathy }\end{array}$ & $\begin{array}{l}\text { Primary } \\
\text { Prevention }\end{array}$ & $\begin{array}{l}\text { Secondary } \\
\text { Prevention }\end{array}$ & $\begin{array}{l}P \\
\text { value }\end{array}$ \\
\hline Number of patients, $n$ & 70 & 39 & 31 & \\
\hline Sex (male), n (\%) & $52(74)$ & $29(74)$ & $23(74)$ & 0.987 \\
\hline $\begin{array}{l}\text { Age at implantation, mean } \\
\text { (range) }\end{array}$ & $63(27-81)$ & $61(27-81)$ & $65(40-81)$ & 0.097 \\
\hline Mean follow up, months (SD) & $117(23)$ & $117(25)$ & $117(20)$ & 0.985 \\
\hline 5-year mortality, n (\%) & $11(16)$ & $6(15)$ & $5(16)$ & 0.932 \\
\hline $\begin{array}{l}\text { Type of device, ICD n (\%), } \\
\text { CRT-D n (\%) }\end{array}$ & 44 (63), 26 (37) & $\begin{array}{l}19(39), 20 \\
(51)\end{array}$ & $\begin{array}{l}25(81), 6 \\
(19)\end{array}$ & 0.006 \\
\hline Average LVEF, \% & 29 & 28 & 30 & 0.440 \\
\hline $\begin{array}{l}\text { Generator changed, including } \\
\text { upgrades, n (\%) }\end{array}$ & $46(66)$ & $26(67)$ & $20(65)$ & 0.851 \\
\hline
\end{tabular}

\begin{tabular}{lllll} 
Abstract 95 Table 2 & ICD therapy and complications & \\
\hline & $\begin{array}{l}\text { Non-ischaemic } \\
\text { Cardiomyopathy }\end{array}$ & $\begin{array}{l}\text { Primary } \\
\text { prevention }\end{array}$ & $\begin{array}{l}\text { Secondary } \\
\text { Prevention }\end{array}$ & $\begin{array}{l}\mathrm{P} \\
\text { value }\end{array}$ \\
\hline $\begin{array}{l}\text { Appropriate ATP or shock, } \mathrm{n}(\%) \\
\text { Median time to 1st appropriate }\end{array}$ & $29(41)$ & $18(46)$ & $11(35)$ & 0.386 \\
$\begin{array}{l}\text { therapy, months (IQR) } \\
\text { Appropriate shock, n (\%) }\end{array}$ & $19(27)$ & $27(12-60)$ & $30(12-62)$ & 0.629 \\
$\begin{array}{l}\text { Median time to 1st appropriate } \\
\text { shock, months (IQR) }\end{array}$ & $49(23-90)$ & $38(22-70)$ & $68(40-103)$ & 0.327 \\
$\begin{array}{l}\text { Shock for VF, n (\%) } \\
\text { Inappropriate shock, n (\%) }\end{array}$ & $11(16 \%)$ & $6(15 \%)$ & $5(16 \%)$ & 0.919 \\
Complication, n (\%) & $9(13)$ & $4(10)$ & $2(6)$ & 0.572 \\
\hline
\end{tabular}

Results The baseline patient characteristics are presented in table 1 and show similar characteristics between the primary and secondary prevention groups, except for a higher level of CRT-D implantation in the primary prevention group $(p=0.006)$. Table 2 shows therapy that the device delivered and complication rates.

Overall, $16 \%$ of patients with an ICD for non-ischaemic cardiomyopathy received a shock for VF. $41 \%$ of patients received appropriate therapy (Shocks or Anti-Tachycardia Pacing) from their ICD with median time to first therapy of 30 months (IQR 12-66). Shocks for VF were similar in each group $(15 \%$ vs. $16 \%, p=0.919)$. Six patients $(8.6 \%)$ had inappropriate shocks and two inappropriate ATP (2.9\%). 9 (13\%) of patients had a complication either at implant or during follow-up; two had pericardial effusions following implant of which one required pericardiocentesis, three required lead replacement due to lead failure, two developed device infections, one was anticoagulated for a lead thrombus and one patient's device failed to treat VF.

Conclusion $16 \%$ of non-ischaemic cardiomyopathy patients received a shock for $\mathrm{VF}$ and $41 \%$ received ICD therapy for VT or VF over a mean follow-up of almost 10 years. This was seen in both primary and secondary prevention. Inappropriate shocks and life-threatening complications were uncommon.

Conflict of Interest Nil

\section{RAPID ROLLOUT OF A PACEMAKER HOME MONITORING SERVICE IN SOMERSET DURING THE 2020 COVID-19 PANDEMIC}

Guy Furniss, Jonathan Shurlock*, Mark Dayer, Rachael Heatley, Lauren Wilson, Bethany Gratton, Mark Roach. Somerset NHS Foundation Trust, Taunton, UK

\subsection{6/heartjnl-2021-BCS.95}

Introduction In an effort to reduce non-essential face to face contact during the COVD pandemic our pacemaker service was restructured in March 2020 to home monitoring only. Home monitors were issued at implant and wound reviews were done remotely via photo messages at one month or if prompted by the patient. Existing patients were given monitors on an ad hoc basis. A dedicated physiologist worked off site on home monitoring clinics. We assess the impact on our service and on patient experience of these changes one year after implementation.

Methods Baseline characteristics of age at implant and distance of home address from hospital were collected from all patients undergoing pacemaker home monitoring. Patients were surveyed using an adapted version of the Generic Short Patient Experiences Questionnaire (GS-PEQ). Comparison was made with our standard face-to-face follow-up model (1, 3, and 12 months).

Results Data was collected for 326 patients. 233 received a new permanent pacemaker from March 2020 onwards and 93 existing patients were issued with a home monitor. Average age at pacemaker implant was 80.6 year ( \pm 9.9 years). The average one-way distance from home to outpatient clinic saved was 15.1 miles $( \pm 10.4) .567$ face-to-face appointments were saved. In an average day the off-site physiologist reviewed over 100 patient records, contacted 10 patients by phone and dictated reports on 20 patients (14 clinic patients and 6 home monitor alerts).Of patients surveyed $88 \%$ agreed with the statement 'I feel safe being cared for solely with a remote monitoring service', $84 \%$ agreed with the statement 'I receive the same standard of care via remote monitoring and face-toface appointments'. Time saved by avoiding a face to face appointment was more than 1 hour for $90 \%$ of respondents. Those surveyed requested communication of reassuring monitoring, the ability to contact the pacing team in the event of concerns and clearer instructions for the home monitoring device.

Only 34\% of newly implanted patients were able to send a photo message of their wound at one month without prompting or assistance. We did not get a post procedure photo in $38 \%$ and the rest either spoke to us about the wound or had a face-to face visit. There was a significant difference in mean age between those who sent a photo (73.72) and those who didn't (81.38) ( $\mathrm{P}=0.000607)$.

Conclusion Rapid role out of a remote monitoring service for permanent pacemakers across Somerset was feasible, produced significant savings in clinics and was well received by patients. There were significant time savings for physiologists and patients. However remote wound monitoring in elderly patients was problematic due to the difficulty sending photo messages.

Conflict of Interest Honaria from Biotronik, Fellowship support from Abbott 